\title{
Modelling spring flood in the area of the Upper Volga basin
}

\author{
M. Helms, O. Evdakov, J. Ihringer, and F. Nestmann \\ Institute for Water and River Basin Management, University of Karlsruhe, Germany \\ Received: 23 January 2006 - Revised: 22 May 2006 - Accepted: 3 July 2006 - Published: 26 September 2006
}

\begin{abstract}
Integrated river-basin management for the Volga river requires understanding and modelling of the flow process in its macro-scale tributary catchments. At the example of the Kostroma catchment $\left(16000 \mathrm{~km}^{2}\right)$, a method combining existing hydrologic simulation tools was developed that allows operational modelling even when data are scarce. Emphasis was placed on simulation of three processes: snow cover development using a snow-compaction model, runoff generation using a conceptual approach with parameters for seasonal antecedent moisture conditions, and runoff concentration using a regionalised unit hydrograph approach. Based on this method, specific regional characteristics of the precipitation-runoff process were identified, in particular a distinct threshold behaviour of runoff generation in catchments with clay-rich soils. With a plausible overall parameterisation of involved tools, spring flood events could successfully be simulated. Present paper mainly focuses on the simulation of a 16-year sample of snowmelt events in a meso-scale catchment. An example of regionalised simulation in the scope of the modelling system "Flussgebietsmodell" shows the capabilities of developed method for application in macro-scale tributary catchments of the Upper Volga basin.
\end{abstract}

\section{Introduction}

After its almost complete transformation into a cascade of reservoirs, the water and energy resources of the Volga river offer enormous economic value. On the other hand, the river has been transformed into an unstable system with largescale risk potential, especially due to increased retention times of water and mass in the reservoirs. Therefore, sustainable use of the resources of the Volga river requires the

Correspondence to: $\mathrm{M}$. Helms

(helms@iwg.uka.de) development of appropriate technologies for integrated riverbasin management. This is the aim of the interdisciplinary German-Russian cooperation project "Volga-Rhine" dealing with various aspects of quantitative and qualitative resources management in the Volga basin. Since the flow process is the main dynamic natural boundary condition in the river system, the development of operational simulation tools for prediction and forecast of river flow in the macro scale is crucial in the scope of the project and the major goal of the investigations presented in this paper. According to the basic concept of the project ("Volga-Rhine"), the tools developed for the Volga basin are based on modelling experiences gained during many years in Germany. However, due to different natural conditions and data availabilities in the Volga basin, regional adaption is necessary.

The hydrologic simulation tools were developed for the Kostroma catchment $\left(16000 \mathrm{~km}^{2}\right.$, Fig. 1) in the transition zone of mixed and boreal forests (about $300 \mathrm{~km} \mathrm{NE}$ of Moscow). With respect to regionalised modelling, soil areas of a glacial series and forest fractions occurring in this catchment are representative for large areas of the Upper Volga basin. Annual precipitation depths vary in the range between 400 and $800 \mathrm{~mm}$ (average about $600 \mathrm{~mm}$ ) with a maximum in summer. However, due to maximum evaporation rates in summer and snow accumulation in winter, the flow regime is dominated by a maximum in spring (due to snowmelt). A secondary maximum occurs in autumn.

Due to their widespread occurrence in the Volga basin, we focussed our investigation on areas with clay-rich soils ("debris loam and clay" of a young-moraine area and "loam and clay" of an old-moraine area; Fig. 1). The predominating FAO soil unit of these areas is podzoluvisol. Furthermore, we emphasised snowmelt induced spring floods, which are the dominating hydrologic characteristic under the prevailing climate.

For the appropriate selection of an operational modelling approach, some boundary conditions have to be considered.

Published by Copernicus GmbH on behalf of the European Geosciences Union. 


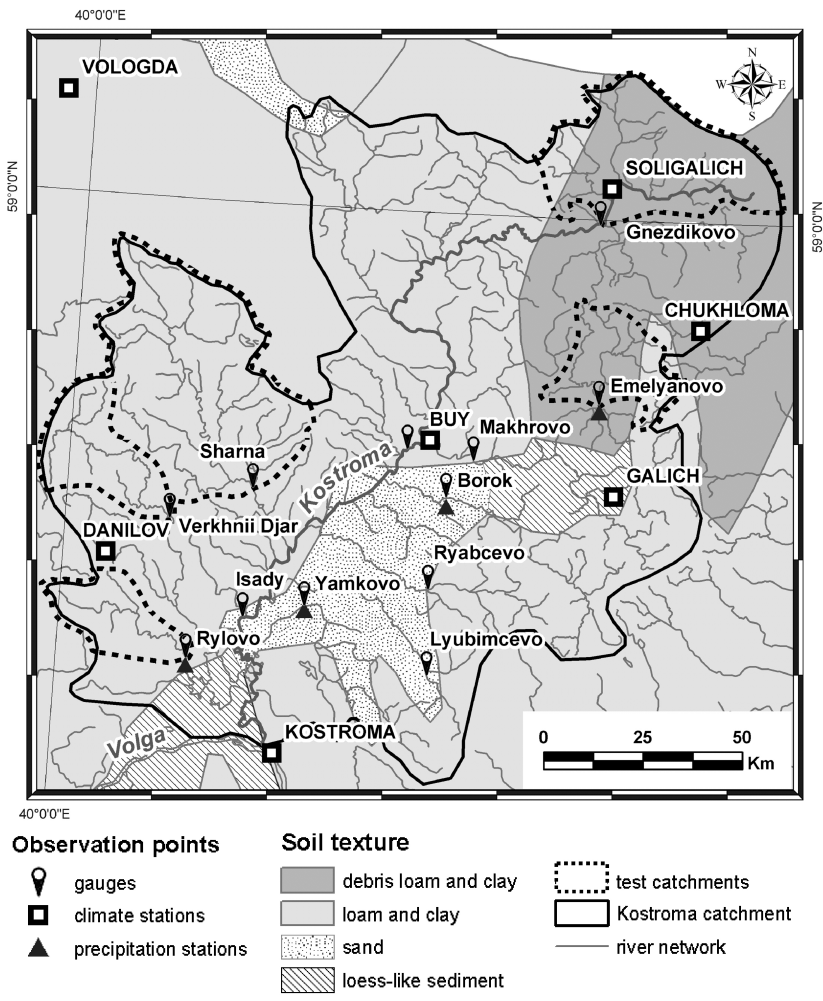

Fig. 1. Soil textures, river network, sites of gauges and meteorological observation stations and defined test catchments in the Kostroma catchment.

At the scale of the investigated catchments, uncertainty concerning interaction of hydrologic processes has to be taken into account (Uhlenbrook, 2005). Particular uncertainty in the study area results from non-linear threshold behaviour of clay-rich soils (Lindenmaier et al., 2005) and data scarcity. Gauges with series of daily flow (1970-1986) and climate stations with series of daily precipitation depth and partly daily air temperature (1970-1990) are shown in Fig. 1. Only in Kostroma and Vologda, detailed meteorological information is available. Information on soil texture (Fig. 1) is based on a map with low spatial resolution (scale 1:2.5 Mio.). Furthermore, a digital map of soil cover (Fig. 2) and a Digital Elevation Model were derived from satellite images (Landsat TM, ASTER).

Regarding these boundary conditions and the goal of operational modelling of the precipitation-runoff (PR) process, parsimonious and robust conceptual modules with semidistributed, representative parameters are adequate to identify and quantify the essential flood-relevant processes at the scale of the major tributaries catchments of the Volga river. For the application of these modules under the specific natural conditions and data availability in the Volga basin, a stepwise procedure controlling uncertainty was developed. The first step consists of the (reliable) simulation of homogeneous hydrologic situations, i.e., events with spatially and tempo- rally homogeneous distribution of input variables and hydrologic states ("test events") in meso-scale catchments with homogeneous properties ("test catchments"). In Sect. 2, properties of runoff generation and runoff concentration are derived for these situations. Based on this knowledge, snowmelt and spring flood events are simulated (Sect. 3). In Sect. 4, perspectives of regionalisation of the modelling approach for macro-scale application are demonstrated. Conclusions are drawn in Sect. 5.

\section{Identification of runoff-generation and runoff- concentration properties}

We selected five meso-scale test catchments: two in a youngmoraine area, and three in an old-moraine area (Fig. 1). In this paper, we focus on the example of the catchment of gauge Emelyanovo $\left(597 \mathrm{~km}^{2}\right)$. Furthermore, we selected 123 snow-free days with significant mean precipitation depths ( $\geq 5 \mathrm{~mm}$ ) of all stations excluding Vologda, and homogeneous spatial distribution (coefficient of variation $\leq 0.33$ ). Measured precipitation depths of the stations were spatially interpolated using the inverse distance-squared method (Smith, 1993) to calculate areal precipitation depths of the test catchments and other sub-catchments of the Kostroma river. Corresponding to above mentioned 123 days, we defined 40 PR test events. The event of May 1978 (Fig. 3) was most suitable for the first step: precipitation was temporally concentrated, snow-free and had a relatively uniform spatial distribution allowing reliable interpolation. Furthermore, the event occurred immediately after a major snowmelt period. Therefore, retention capacity of the catchment of Emelyanovo was very low and hence almost not variable. For this event, a reliable non-parametric unit hydrograph $(U H)$ was derived (Pilgrim and Cordery, 1993).

Using the identified $U H$ and overall runoff coefficients $(R C)$ of the test events, percentage approaches for operational modelling of the temporal distribution of effective precipitation (or conversely loss; Pilgrim and Cordery, 1993) were evaluated. Amongst others, the constant percentage approach (constant loss fraction), the phi-index approach (constant potential loss rate) and the exponential percentage approach (loss fraction exponentially decreasing with time) were considered. As an example, see the constant percentage approach applied on the event of October 1986 (Fig. 4). For this evaluation, effective precipitation depths simulated with the percentage approaches and systematic variations of initial loss $(I L)$ were each convoluted with the $U H$ and diagnosed in comparison to observed hydrographs of direct flow (straightline separation as satisfactory approximation). Like in Fig. 4, the constant-percentage approach produced best fits to the observed direct flow in almost all test events. However, calibrated IL exhibit high seasonal and event-specific variability (values up to $35 \mathrm{~mm}$ in catchment Emelyanovo). On the other hand, high maximum (or final) $R C$ (after subtraction of 


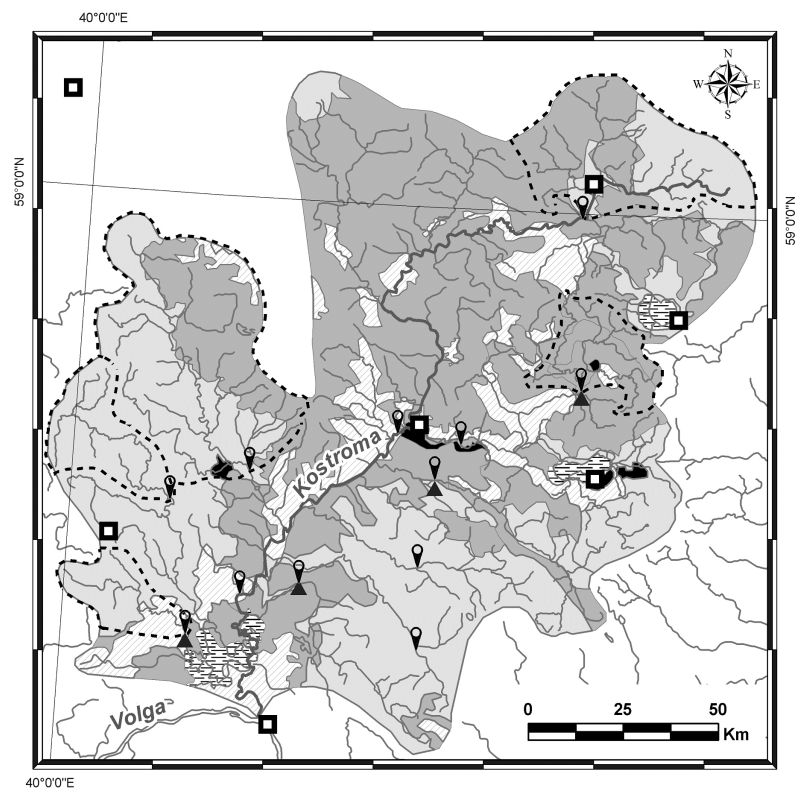

\section{Observation points}

$P$ gauges

- climate stations

A precipitation stations

\section{Landuse}

焉量 lakes

urbanised areas

VIIIA low percentage of forest

$\square$ higher percentage of forest

forest

a............. test catchments
river network

Fig. 2. Soil cover derived from a Landsat TM scene, river network, sites of gauges and meteorological observation stations and defined test catchments in the Kostroma catchment.

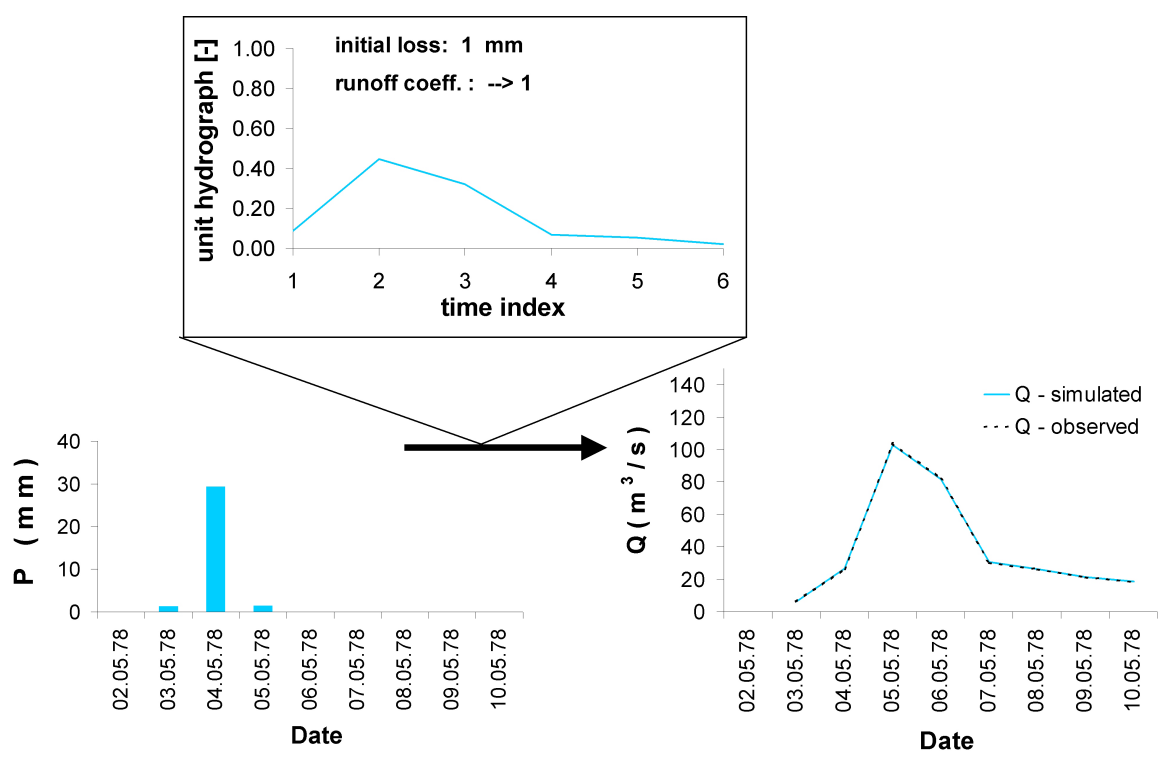

Fig. 3. Derivation of the non-parametric unit hydrograph for a precipitation-runoff event in May 1978 with homogeneous conditions of runoff generation in the test catchment Emelyanovo.

$I L)$ occurred. Both, high maximum $R C$ and high $I L$ result from characteristics of predominating podzoluvisols. It may be assumed that clay depletion in eluvial E-horizons may cause high $I L$ while low water-permeability of illuvial Bthorizons may cause high maximal $R C$. In old-moraine areas, these characteristics of runoff generation are more distinct than in young-moraine areas.

\section{Modelling of snowmelt and spring flood events}

For snow accumulation, precipitation forms were identified using spatially interpolated values of air temperature in comparison to threshold values of transitions between precipitation forms. Regarding the scarcity of meteorological data, the degree-day method (Gray and Prowse, 1993) with time-variant degree-day factor (DDF) was used to model the energy-exchange processes of the snow-cover. Compaction 


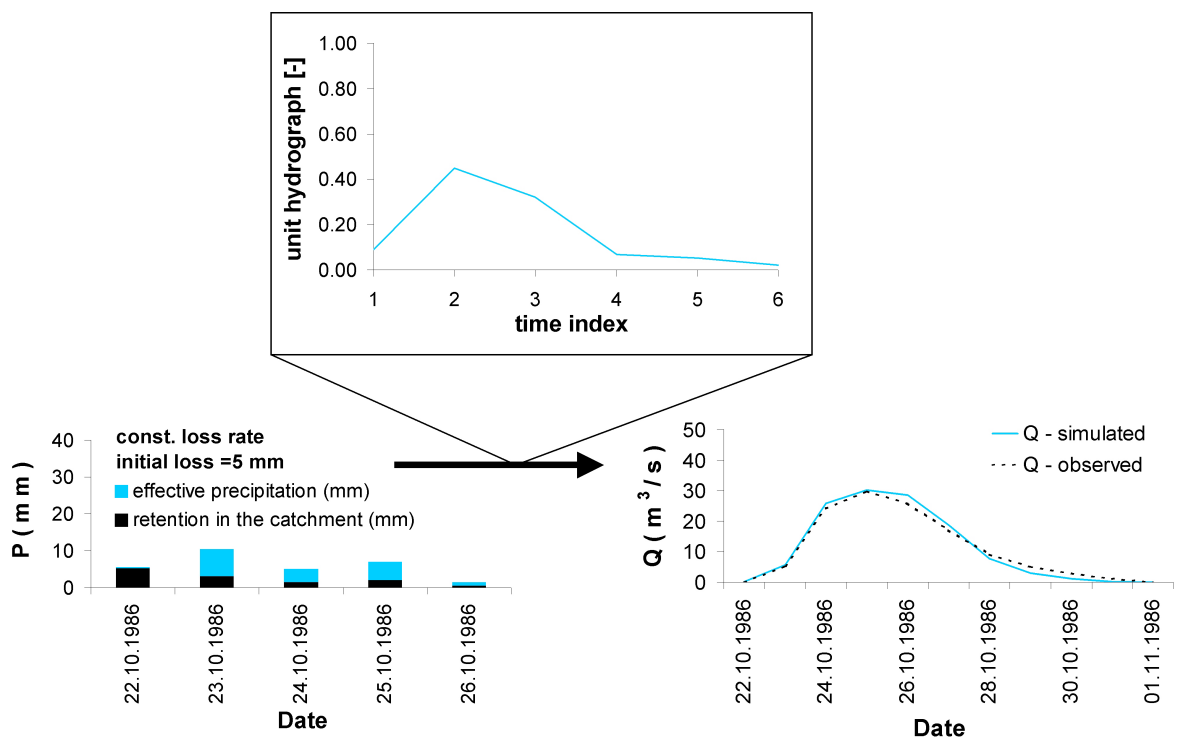

Fig. 4. Derivation of effective precipitation depths for a precipitation-runoff event in October 1986 in the test catchment Emelyanovo using the constant percentage approach with optimised initial loss and the known unit hydrograph.

and retention of liquid water in the snow cover were taken into account in a snow-compaction module (Bertle, 1966). Using these approaches, the development of snow cover and, hence, its water release were simulated. For calibration of the time-variant DDF, we used the criterion that after convolution with the $U H$, water release of the snow cover results in values with constant ratio to observed direct flow in the area of the flood peak (corresponding to the constant percentage approach, see Sect. 2 and Fig. 5). For the almost completely forested catchment of Emelyanovo with relatively low radiation impact, calibrated DDF's are about $0.5 \mathrm{~mm} / \mathrm{d} \cdot \mathrm{K}$ in winter (Fig. 6). In the major melt periods in spring, DDF's vary between about 1.3 (initial melt stage) and about $2.0 \mathrm{~mm} / \mathrm{d} \cdot \mathrm{K}$ (advanced stage with daily mean temperatures continuously greater than $\left.5^{\circ} \mathrm{C}\right)$. An exception is the final melt stage in 1982 (DDF=3.1 mm/d.K; see Fig. 6), however, reduced DDF's (e.g., $2.3 \mathrm{~mm} / \mathrm{d} \cdot \mathrm{K}$ ) result only in a slight shift of the peak of convoluted water release. In autumn (until 30 November), DDF's similar to those in spring $(2.0 \mathrm{~mm} / \mathrm{d} \cdot \mathrm{K})$ may be assumed as satisfactory approximation. These DDF's correspond to those specified for "boreal forest" and "taiga" in Gray and Prowse (1993). Moreover, Fig. 6 shows a plausible development of calibrated DDF's during spring in all years except 1982 (see above) and 1986. In general, scattering may be attributed to different sequences of weather situations and might be explained by more detailed meteorological data (radiation, weather classification).

For the investigated areas with predominating podzoluvisols, we postulate the following hypothesis on the essential processes of runoff generation due to snowmelt (compare Fig. 7): in summer, with negative soil water balance, macropores and hence preferential flow paths are formed due to clay shrinkage in the upper Bt-horizon and in its (diagnostic) interlocking area with the E-horizon. A deeper saturated soil reservoir (excess water typically occurring in podzoluvisols) is filled by infiltrating precipitation water. In autumn, the size of macro-pores is reduced due to wetting of the soil and clay swelling. However, due to typical tonguing of the E-horizon (coarser grained material) into the Bt-horizon, the discussed soil area remains more or less permeable. During winter, this soil state is conserved. Therefore, infiltrating snowmelt water in spring is more or less retained in upper soil horizons before it enters into the saturated reservoir. In an advanced infiltration stage, water is displaced from the saturated reservoir due to hydraulic connection to infiltration water and pressure transmission.

To prove the hypothesis and to transfer it to a conceptual model based on available data (see Sect. 1), regression equations for runoff volume $V O L\left[\mathrm{~m}^{3}\right]$ and $I L\left[\mathrm{~m}^{3}\right]$ of flood events due to snowmelt were developed (Eqs. (1) and (3), for the catchment of Emelyanovo). Overall $R C \Psi$ was calculated according to Eq. (2). Regressors in Eqs. (1) and (3) were selected among:

- event parameter: volume $\Sigma I\left[\mathrm{~m}^{3}\right]$ of system input $I$ (= water release of the snow cover);

- state/memory parameters describing moisture conditions: volumes of base flow $Q B\left[\mathrm{~m}^{3}\right]$ (Duband et al., 1993) for summer and autumn of the antecedent year (June-September $\Sigma Q B_{J S}$; October-December $15 \Sigma Q B_{O D}$; see Fig. 8), and - in Eq. (3) - overall $R C$ $\Psi$ during the flood event.

In one year (1978/1979), $\Sigma Q B_{O D}$ and in particular $\Sigma Q B_{J S}$ were much greater than in all other years, which were 


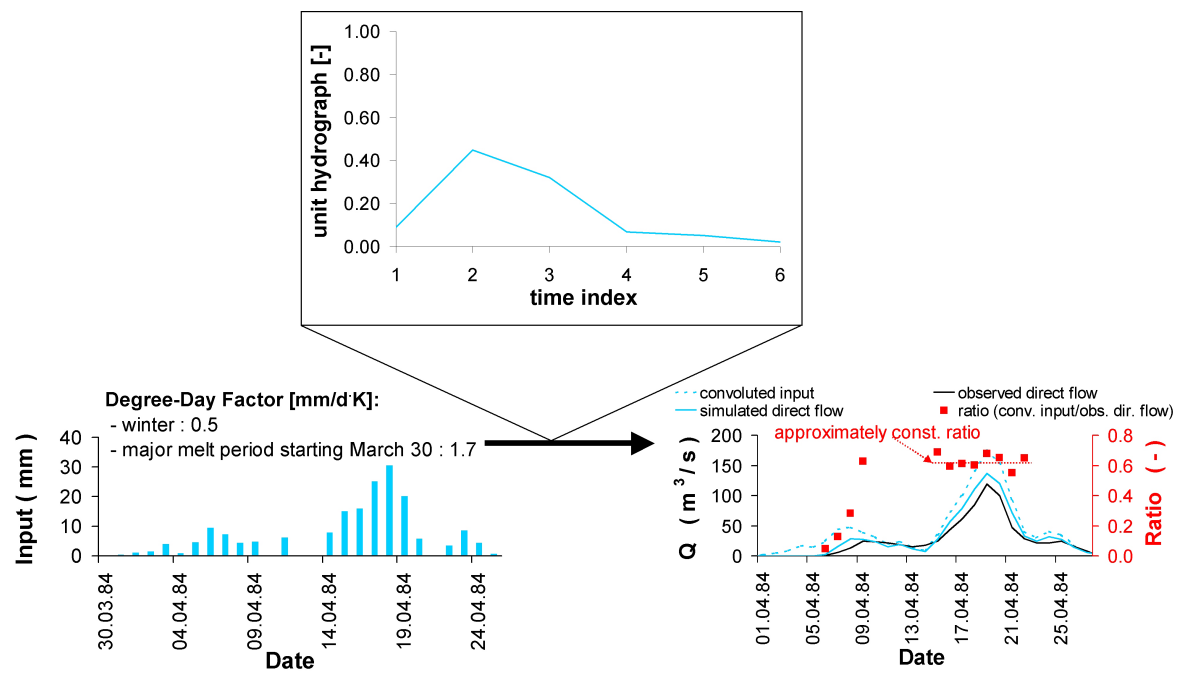

Fig. 5. Calibration of a snow model for spring 1984 in catchment Emelyanovo using the criterion of constant daily ratios between convoluted water release of the snow cover and observed direct flow in the area of the flood peak. In addition, direct flow simulated with the constant percentage approach and parameters estimated with a regression approach is shown.

analysed. $I L$ was zero and $\Psi$ about one in spite of a relatively low $\Sigma I$. Since Eq. (3) would be strongly biased by this single year, the latter was excluded from the analysis of $I L$ and a case differentiation was made. Since no significant bias was found in Eq. (1), the complete series could be analysed with respect to $V O L$.

$\log (V O L)=-4.7+1.28 \cdot \log (\Sigma I)+0.31 \cdot \log \left(\Sigma Q B_{J S}\right)$

$\Psi=V O L / \Sigma I$

$I L=5.48 \cdot 10^{6}+29.27 \cdot 10^{6} \cdot \Psi-0.15 \cdot \Sigma I$

Coefficients of determination of the analysed series show good fits to observed VOL $\left(R^{2}=0.82\right.$ for Eq. (1); $R^{2}=0.86$ after back-transformation) and calibrated $I L\left(R^{2}=0.89\right)$. Since correlation among the regressors is low $\left(R^{2} \leq 0.07\right)$, it may be assumed that collinearity is weak. However, to validate Eq. (1) and (3), split-sample tests were performed (sample 1: 1970/1971-1977/1978; sample 2: 1978/1979-1985/1986 or 1979/1980-1985/1986), i.e., parameters determined from sample 1 were assigned to sample 2 and vice versa. For both equations, regression coefficients remain in the same order of magnitude in the subdivided samples, and coefficients of determination of the overall series remain high: $R^{2}=0.76$ ( $R^{2}=0.80$ after back-transformation) for Eq. (1) and $R^{2}=0.85$ for Eq. (3).

Introduction of the regressor $\Sigma Q B_{O D}$ (see Eq. (4) for $V O L)$ improves the fits: $R^{2}=0.86\left(R^{2}=0.90\right.$ after backtransformation) for $V O L$ and $R^{2}=0.91$ for $I L$.

$$
\begin{aligned}
\log (V O L)= & -5.7+1.35 \cdot \log (\Sigma I)+0.23 \cdot \log \left(\Sigma Q B_{J S}\right) \\
& +0.15 \cdot \log \left(\Sigma Q B_{O D}\right)
\end{aligned}
$$

However, collinearity has to be considered due to higher correlation among $\log \Sigma Q B_{O D}$ and $\log \Sigma Q B_{J S}\left(R^{2}=0.25\right)$.

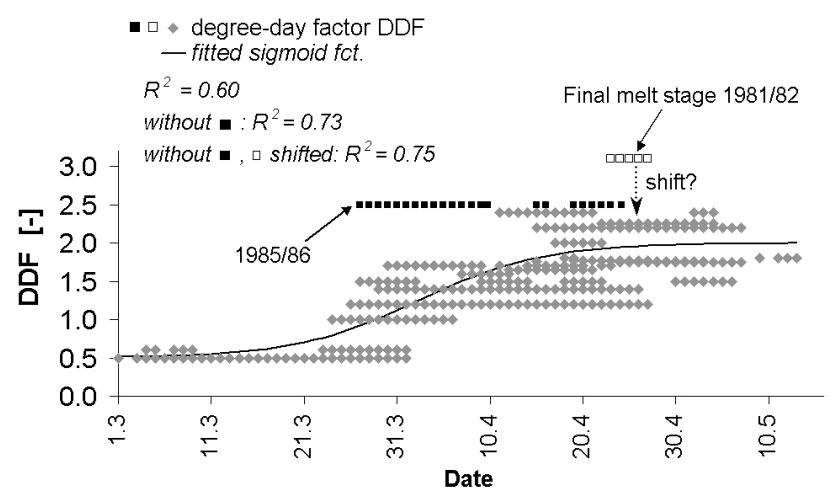

Fig. 6. Degree-day factors (DDF's) of the melting seasons 19701986 in catchment Emelyanovo derived from diagnosis of a snowcompaction model using river flow as reference variable. Plausible development of the DDF's is diagnosed by a fitted sigmoid fct. with the specified coefficients of determination R2. Uncertain DDF's occur in the years 1982 and 1986.

In a split-sample test, the regression coefficient of $\log \left(\Sigma Q B_{O D}\right)$ was confirmed in sample 1 (with relatively low $\Sigma Q B$-values; coefficient 0.17 ), but not in sample 2 (with relatively high $\Sigma Q B$-values; coefficient 0.05 ). However, using the equation derived from sample 1 , the fit to sample 2 is almost as good as the fit of the equation derived from sample 1 itself ( $R^{2}=0.85$ vs. 0.87 ). Therefore, validation of Eq. (4) was at least partly successful. For $I L$, validation of the equation including $\Sigma Q B_{O D}$ was less successful due to unstable regression coefficients of $\Sigma Q B_{O D}$ in the subdivided samples and due to a coefficient of determination of the overall series less than those of the validation of Eq. (3) $\left(R^{2}=0.83\right.$ vs. 0.85). 

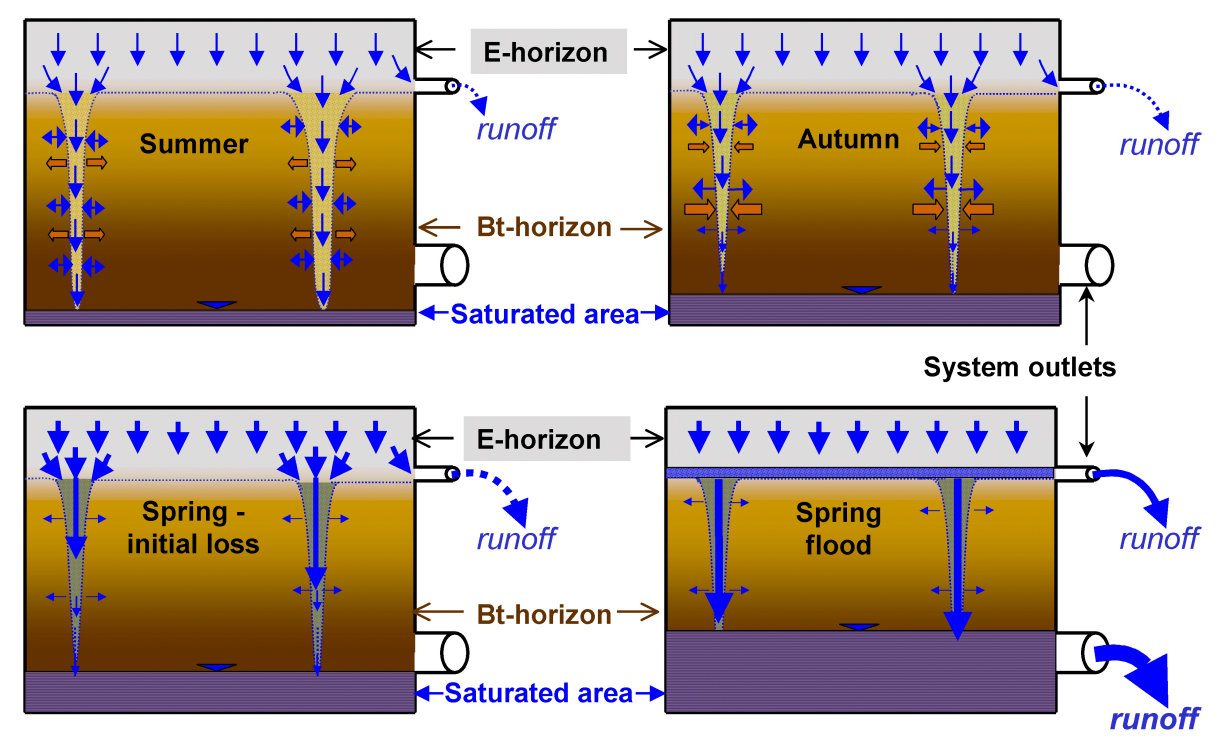

Fig. 7. Scheme of the discussed runoff-generation mechanism of spring flood events in catchments with predominating podzoluvisols. Blue arrows indicate dynamics of soil water, brown block arrows those of the soil matrix due to shrinkage or swelling of clay.

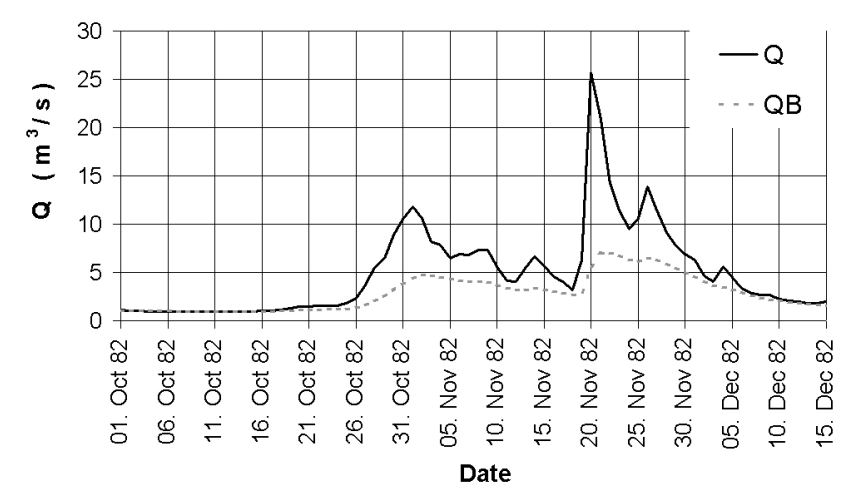

Fig. 8. Flow hydrograph $(Q)$ of autumn 1982 at the gauge of Emelyanovo and baseflow $(Q B)$ calculated according to Duband et al. (1993) by an auto-regressive approach, which uses the exogeneous variable "direct flow" and which was calibrated according to an analysis of recession curves.

Regarding above hypothesis, these results may be interpreted as follows:

Positive impact of $\Sigma I$ on $V O L$ is evident. Furthermore, $\log \left(\Sigma Q B_{O D}\right)$ and in particular $\log \left(\Sigma Q_{J S}\right)$ explain considerable variance fractions of $\log (V O L)$ and confirm positive dependence of $V O L$ on moisture conditions in summer and autumn of the antecedent year.

Also $I L$ depends on the interaction of input (reducing impact) and moisture conditions in soil (amplifying impact due to reduced permeability). Analyses revealed that the essential variance fraction of $I L$ may be explained using the lumped parameters $\Sigma I$ and $\Psi$. Further differentiation (using the regressors $\Sigma Q B_{O D}$ and $\Sigma Q B_{J S}$ ) does not improve the statistical properties of the model. However, in years with very wet conditions in the antecedent summer and autumn (e.g., 1978/1979), IL may become zero, apparently due to the high initial elevation of the water table of the saturated reservoir and the high soil water content in the E-horizon. The exact critical conditions for the switch from application of Eq. (3) to the assumption that $I L$ is zero still cannot be quantified based on available data.

Finally, flood events were simulated using the constant percentage approach and estimated parameters ( $\Psi$ and $I L$ according to Eqs. (2), (3), and (4))). As an example, see the event of 1984 in Fig. 5). Nash-Sutcliffe efficiency criteria $(E C)$ for single events vary between 0.53 and 0.93 , except those of 1971 and 1986 ( $E C=0.41$ and 0.15$)$. However, for all events, the overall $E C$ of 0.80 ( $E C=0.87$ if 1986 is excluded) confirms the adequacy of the model. In the validation of the model, the $E C$ is in the same order of magnitude ( $E C=0.77 ; E C=0.84$ if 1986 is excluded).

\section{Perspectives toward regionalisation and macro-scale modelling}

For the test events (Sect. 2), similar runoff-generation properties among the test catchments within considered soil areas were found. For snowmelt events (Sect. 3), a comparison of runoff-generation properties was still not reliable due to lower or mixed forest fractions in some test catchments increasing uncertainty of the DDF (radiation impact). To evaluate transferability, test catchments with high and homogeneous forest fractions in other areas of the Upper Volga basin should be considered first. In case of confirmed transferability, the regionalised application of the model, e.g., 


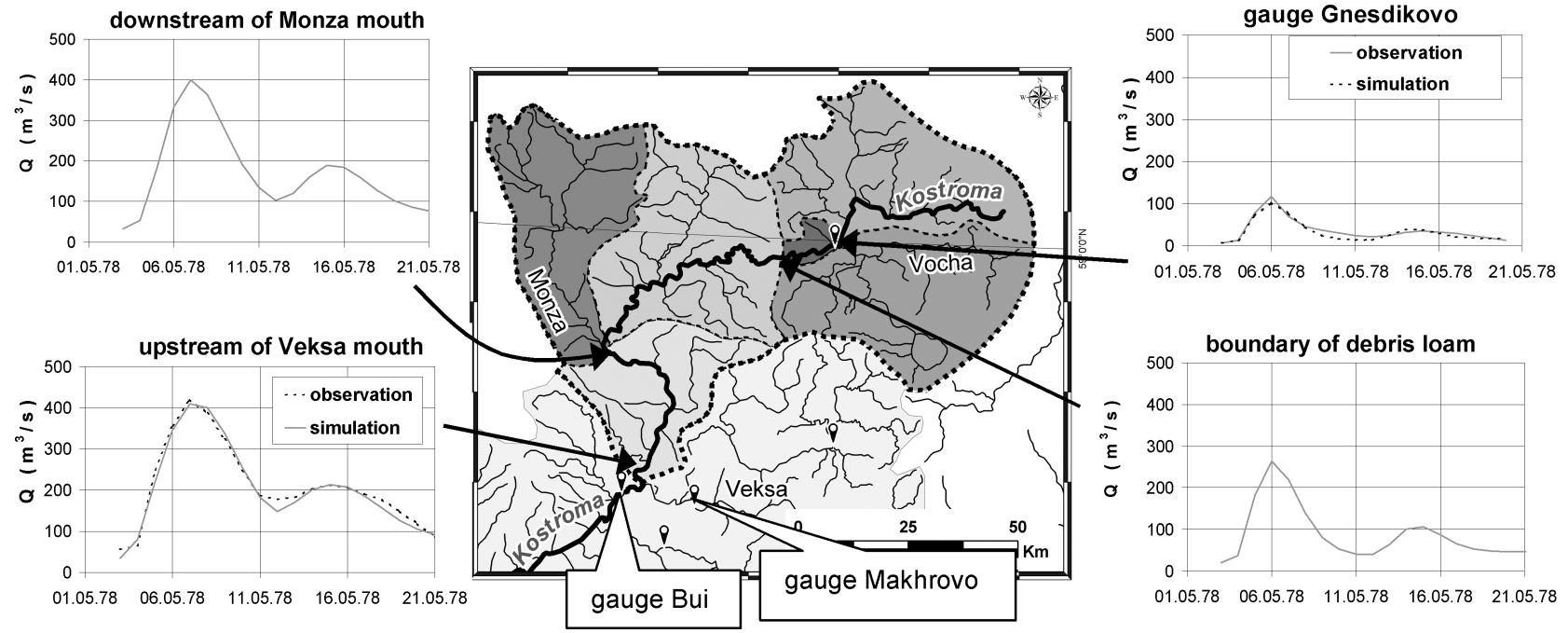

Fig. 9. Kostroma catchment upstream of the Veksa mouth: simulated hydrographs of the flood event in May 1978 for selected sites along the Kostroma river. The "observed" hydrograph at the lowest site was calculated as difference of the hydrographs in Bui and Makhrovo (the latter multiplied with 1.1 to account for the unobserved area downstream of the gauge).

for generalised diagnosis of the snow model or macro-scale simulation including unobserved catchments, will require regionalisation of a parameterised $U H$. According to Plate et al. (1988), the time to peak $t_{A}$ of the $U H$ is related to catchment parameters. These parameters may be derived with a Geographic Information System (GIS):

$t_{A}=P 1 \cdot\left(\frac{L \cdot L_{C}}{I_{W}^{1.5}}\right)^{0.26} \cdot e^{-0.016 \cdot u} \cdot e^{0.004 \cdot f} \cdot a_{1} \cdot a_{2} \cdot a_{3}$

with $L, L_{C}$ (length of the major watercourse between the mouth and the watershed, and between the mouth and a line perpendicular to the centroid of the catchment), $I_{w}$ (weighted slope of the watercourse; Plate et al., 1988), $u, f$ (urbanised and forested fraction of the catchment in \%, compare Fig. 2) and $P 1$ (calibrated catchment factor). Correction factors $a_{1}$ to $a_{3}$ account for event characteristics (precipitation intensity, season, $R C$; Plate et al., 1988). The peak value of the $U H u_{\max }$ is calculated from $t_{A}$, coefficients $b$ and $c$ depending on time step and the correction factor $u_{\text {cor }}$ accounting for retention effects without influence on $t_{A}$.

$u_{\max }=u_{\mathrm{cor}} \cdot b \cdot t_{A}^{c}$

Based on extensive experience in application of the regionalisation approach in Germany (including moraine areas), only $P 1$ and $u_{\text {cor }}$ need calibration. With $t_{A}$ and $u_{\max }$, parameters $n$ and $k$ of the Nash cascade (parametric $U H$ ) may be derived (Plate et al., 1988). In the test catchments, $P 1$ was calibrated for an optimal fit of parametric to non-parametric $U H$ 's. Significant differences between young-moraine areas $(P 1 \cong 0.18)$ and old-moraine areas $(P 1 \cong 0.10)$, and minor differences within these areas indicate that $P 1$ may be transferred to unobserved catchments for regionalisation of the $U H$. Similar conclusions were drawn for $u_{\text {cor }}$.

The approach was applied to the event of May 1978 in the Kostroma catchment upstream of the Veksa mouth $\left(6000 \mathrm{~km}^{2}\right.$, see Fig. 9). Meso-scale sub-catchments with each homogeneous soil properties were defined using the GIS. Furthermore, the structure of the river network and the position of gauges were taken into account. Using properties of runoff generation identified for this event (see Sect. 2), interpolated meteorological parameters and regionalised $U H$ 's, direct flow could be simulated also for unobserved catchments. For each soil area, base flow was regionalised assuming simple linear dependence from catchment area. The good fit of the simulation to the observed event at gauge Gnesdikovo (Fig. 9) confirms the adequacy of the regionalised model. Finally, the event was simulated for the overall catchment of the Kostroma upstream of the Veksa mouth using above described modules in the framework of the "Flussgebietsmodell" - FGM (Ihringer, 1999). To couple the modules, flood routing for the watercourse of the Kostroma (model of Kalinin and Miljukov, see Plate (1977)) was included. Results of the simulation at selected sites along the Kostroma river with increasing peak and volume of the flood wave are shown in Fig. 9. At the catchment outlet, simulated and observed hydrographs (derived from observations at the gauges Bui and Makhrovo) match well.

\section{Conclusions}

A stepwise procedure was developed for operational modelling of PR processes under specific natural conditions and 
with scarce data availability in the Upper Volga basin. Emphasis was placed on spring floods in areas of clay-rich soils including the following processes:

- Runoff concentration: a regionalised $U H$ for meso-scale catchments was derived. Beside modelling of runoff concentration, it may serve for the diagnosis of modules for runoff generation and snow-cover development using river flow as available reference variable.

- Runoff generation: distinct threshold behaviour of clayrich soils (podzoluvisols) depending on season and time-variant state, was identified. Due to the systems memory, impact of moisture conditions of the antecedent year on runoff generation in spring was found. A hypothesis on a corresponding mechanism of runoff generation was largely verified in a conceptual model. Further improvement of the model would require additional data and might be achieved by its empirical proof (analysis of longer periods and additional catchments to increase statistical evidence) or by its process-based differentiation including inspection of soil profiles in different seasons, acquisition of soil-moisture data and tracer experiments to separate event water and pre-event water.

- Snow-cover development: a continuously working snow-compaction model with time-variant DDF was successfully applied for forested catchments. However, additional analyses should be performed, especially for catchments with lower forest fraction. If possible, analyses should include additional meteorological data (snow depths, radiation, weather situations).

Altogether, a plausible overall picture of the essential flood-relevant processes in the Kostroma catchment could be achieved by combined application of the described tools. Regionalised simulation using FGM as core module shows its capabilities in the complete simulation of PR processes in macro-scale catchments of the Volga basin. Furthermore, the modular structure of FGM enables substitution and comparison of individual modules. It may thus serve as base for efficient evaluation of different simulation techniques, especially concerning runoff generation and snow-cover development, which should include regional modelling experiences of Russian scientists. Beyond this hydrologic aspect, the operational modelling system opens the perspective of integrated river basin management in the Upper Volga basin (compare Sect. 1).
Acknowledgements. The research has been supported by the German Federal Ministry for Education and Research (grant 02WT0094). The authors are grateful to the partners at the University of Architecture and Civil Engineering in N. Novgorod (S. V. Sobol, A. V. Fevralev) and the All-Russian Research Inst. for Hydraulic Engineering and Land Reclamation (A. Shcherbakov) for valuable discussions and support in data collection. Thanks are due to F. Lindenmaier, Inst. of Water and River Basin Management/University of Karlsruhe, for valuable discussions.

Edited by: R. Barthel, J. Götzinger, G. Hartmann, J. Jagelke, V. Rojanschi, and J. Wolf

Reviewed by: anonymous referees

\section{References}

Bertle, F. A.: Effect of Snow Compaction on Runoff from Rain on Snow, Bureau of Reclamation, Engineering Monograph, 35, 45p., Washington, 1966.

Duband, D., Obled, Ch., and Rodriguez, J. Y.: Unit hydrograph revisited: an alternate iterative approach to $U H$ a, effective precipitation identification, J. Hydrol., 150, 115-149, 1993.

Gray, D. M. and Prowse, T. D.: Snow and Floating Ice, in: Handbook of Hydrology, edited by: Maidment, D. R., McGraw-Hill, Inc., New York, 1993.

Ihringer, J.: Softwarepaket für Hydrologie u. Wasserwirtschaft (Software package for Hydrol. Water Res. Manag.). Dpmt. of Wat. and River Basin Man., Univ. of Karlsruhe, 1999.

Lindenmaier, F., Zehe, E., Helms, M., Evdakov, O., and Ihringer, J.: Effect of Soil Shrinkage on Runoff Generation in Microand Meso-Scale Catchments, edited by: Sivapalan, M., PUB: Promises and Progress, IAHS-Publ. No. 303, 305-317, Wallingford, 2006.

Pilgrim, D. H. and Cordery, I.: Flood Runoff, in: Handbook of Hydrology, edited by: Maidment, D. R., McGraw-Hill Inc., New York, 1993.

Plate, E.: Ablauf von Hochwasserwellen in Gerinnen (Routing of flood waves in river channels), Parey, Hamburg, 1977.

Plate, E., Ihringer, J., and Lutz, W.: Operational Models for Flood Calculations, J. Hydrol., 100, 489-506, 1988.

Smith, J. A.: Precipitation, in: Handbook of Hydrology, edited by: Maidment, D. R., McGraw-Hill, Inc., New York, 1993.

Uhlenbrook, S.: Von der Abflussbildungsprozessforschung zur prozess-orientierten Modellierung (From Research in the Process of Runoff Generation Towards Process-Oriented Modelling), Hydrol. und Wasserbewirtschaftung (Hydrol. Wat. Res. Manag.), 49(1), 13-24, 2005. 